\title{
Multilocular Thymic Cyst
}

National Cancer Institute

\section{Source}

National Cancer Institute. Multilocular Thymic Cyst. NCI Thesaurus. Code C45379.

A multicystic lesion that arises from the epithelial component of the thymus gland. It is usually associated with the presence of lymphoid follicles and degenerative changes.

Although its etiology is unknown, it has been described in patients with HIV infection and in patients with nodular sclerosis Hodgkin lymphoma affecting the thymus gland. 